\title{
VIVÊNCIA FAMILIAR DO ATENDIMENTO DE EMERGÊNCIA
}

\section{FAMILY EXPERIENCE OF EMERGENCY CARE}

\section{EXPERIENCIA FAMILIAR DE ATENCIÓN DE EMERGENCIA}

\author{
Mayckel da Silva Barreto ${ }^{1}$ \\ Sonia Silva Marcon ${ }^{2}$ \\ Cristina Garcia-Vivar ${ }^{3}$ \\ Eleandro do Prado ${ }^{4}$ \\ Josane Rosenilda da Costa ${ }^{5}$ \\ Patrícia Chatalov Ferreira ${ }^{6}$ \\ Ricardo de Souza Campos Seguraço ${ }^{7}$
}

Como citar este artigo: Barreto MS, Marcon SS, Garcia-Vivar C, Prado E, Costa JR, Ferreira PC, et al. Vivência familiar do atendimento de emergência. Rev baiana enferm. 2020;34:e35100.

Objetivo: compreender como a família percebe a vivência do atendimento emergencial a um de seus membros. Método: estudo descritivo de natureza qualitativa, realizado em três municípios do Sul do Brasil. Os dados foram coletados em junho de 2015 por meio de entrevistas semiestruturadas, realizadas no domicílio de 16 indivíduos que acompanharam seus familiares em unidade emergencial. As entrevistas foram gravadas, transcritas e submetidas à Análise de Conteúdo, modalidade temática. Resultados: as famílias revelaram intenso sofrimento durante o atendimento emergencial de seu familiar. A rapidez e resolutividade no atendimento, a presença de comunicação efetiva e a possibilidade de acompanhar a assistência foram percebidas pelos familiares, quando presentes, como qualificadores do atendimento e, quando ausentes, como desqualificadores. Conclusão: a vivência familiar durante o atendimento emergencial foi caracterizada por intenso sofrimento, o qual é diretamente influenciado pelo modo como os profissionais de saúde acolhem e atendem o paciente e sua família.

Descritores: Família. Relações Profissional-família. Serviços Médicos de Emergência.

Objective: to understand the family perception on the experience of emergency care to one of its members. Method: descriptive study of qualitative nature, carried out in three municipalities in Southern Brazil. Data were collected in June 2015 through semi-structured interviews, held in the bome of 16 individuals who accompanied their relatives in the emergency unit. The interviews were recorded, transcribed and submitted to thematic Content Analysis. Results: the families revealed intense suffering during the emergency care with the family member. The fast and effective care, the presence of effective communication and the possibility to monitor the assistance were perceived by the family, when present, as care qualifiers and, when absent, as disqualifiers. Conclusion: the family life during the emergency care has been characterized by intense suffering, which is directly influenced by bow bealth professionals receive and meet the patient and his/her family.

Descriptors: Family. Professional-family relations. Emergency Medical Services.

\footnotetext{
Enfermeiro. Doutor em Enfermagem. Professor da Faculdade de Filosofia, Ciências e Letras de Mandaguari. Mandaguari, Paraná, Brasil. mayckelbar@gmail.com. https://orcid.org/0000-0003-2290-8418.

Enfermeira. Doutora em Filosofia da Enfermagem. Professora da Universidade Estadual de Maringá. Maringá, Paraná, Brasil. https://orcid.org/0000-0002-6607-362X.

Enfermeira. Doutora em Enfermagem. Professora da Universidade de Navarra. Pamplona, Navarra, Espanha. https://orcid.org/0000-0002-6022-559X.

Enfermeiro. Mestre em Enfermagem. Professor da Faculdade Guiaracá. Guarapuava, Paraná, Brasil. https://orcid.org/0000-0003-2403-5462.

Enfermeira. Mestre em Enfermagem. Universidade Estadual de Maringá. Maringá, Paraná, Brasil. https://orcid.org/0000-0003-0369-977X.

Enfermeira. Especialista em Enfermagem nas Emergências. Universidade Estadual de Maringá. Maringá, Paraná, Brasil. https://orcid.org/0000-000 I-9409-5888.

Enfermeiro. Especialista em Anatomia Humana e Histológica. Universidade Estadual de Maringá. Maringá, Paraná, Brasil. https://orcid.org/0000-0002- 1075 - 1962.
} 
Objetivo: comprender cómo la familia percibe la experiencia de atención de urgencia a uno de sus miembros. Método: estudio descriptivo de carácter cualitativo, realizado en tres municipios del Sur de Brasil. Los datos fueron recolectados en junio de 2015 mediante entrevistas semi-estructuradas, realizadas en la casa de las 16 personas que acompañaron a sus familiares en la unidad de urgencias. Las entrevistas fueron grabadas, transcritas y sometidas a Análisis de Contenido temático. Resultados: las familias revelaron intenso sufrimiento durante los cuidados de emergencia para su miembro. La rapidez y la eficacia en la atención, la presencia de una comunicación efectiva y la posibilidad de monitorear la asistencia fueron percibidas por la familia, cuando presentes, como calificadores de cuidado y, cuando ausentes, como descalificadores. Conclusión: la vida familiar durante la atención de emergencia se ha caracterizado por un intenso sufrimiento, que está directamente influenciado por cómo los profesionales de la salud reciben y atienden al paciente y su familia.

Descriptores: Familia. Relaciones Profesional-familia. Servicios Médicos de Urgencia.

\section{Introdução}

As unidades de emergência destinam-se a promover assistência à saúde com caráter urgente e tem por objetivo prolongar a vida ou prevenir consequências críticas aos pacientes ${ }^{(1)}$. Constituem uma das principais alternativas de acesso aos serviços de saúde, ainda que a política de atendimento pautada nas Redes de Atenção à Saúde aponte a Atenção Básica como porta de entrada preferencial. Isso ocorre porque, de acordo com os usuários, as unidades emergenciais congregam diferentes recursos - consultas médicas, exames laboratoriais, medicamentos, procedimentos de enfermagem e intervenções - que usualmente atendem suas expectativas e necessidades ${ }^{(2)}$. Assim, em muitas situações, inclusive em casos de pouca ou nenhuma urgência, os usuários buscam tais unidades como primeira opção ${ }^{(3-4)}$.

A demanda espontânea e irrestrita, quase sempre superior àquela comportada pelos serviços, desencadeia superlotação e dificulta a transferência de pacientes críticos a setores hospitalares de internação com maior densidade tecnológica ${ }^{(5)}$. Ainda, a precariedade de recursos humanos e materiais e de infraestrutura física adequada, dificultam, sobretudo, a manutenção da privacidade do indivíduo e sua família, bem como a atuação da equipe ${ }^{(6)}$. Essa realidade é compartilhada por diferentes unidades emergenciais e constitui-se em um dos determinantes para que a família não seja acolhida de modo qualificado nesses espaços.

Devem-se considerar também as características específicas dos pacientes em estado grave admitidos nos serviços emergenciais. Estes demandam assistência imediata dos profissionais, e consequentemente, a atenção da equipe volta-se exclusivamente à vítima até a estabilização do quadro $^{(7)}$. Tal fato auxilia na compreensão das razões que levam os profissionais a solicitarem que os familiares aguardem o término do atendimento na recepção da unidade ou em sala de espera. Entretanto, a literatura sobre o tema ${ }^{(2,7-8)}$ aponta que um indivíduo, ao receber a notícia de que seu familiar necessita de cuidados intensivos e agudos, apresenta um conjunto de sentimentos e sensações, como estranhamento, ansiedade, impotência e medo, o que pode acarretar desequilíbrio emocional e, possivelmente, uma crise familiar ${ }^{(2)}$. Somado a isto, a falha na comunicação entre o binômio profissionalpaciente - reflexo da omissão de informações em tempo oportuno, com a exclusão da família nas decisões relacionadas ao tratamento instituído e do uso de termos complexos nesse diálogo - coopera para que as famílias se tornem mais confusas e estressadas ${ }^{(8)}$.

Nessa conjuntura, quando inquiridas, as famílias dos pacientes classificaram a necessidade de informação compartilhada, comunicação hábil, apoio e proximidade com seus entes como prioridades na assistência recebida ${ }^{(1,9)}$. Pensar e repensar a família em situações altamente estressoras para o núcleo familiar, como é o caso do atendimento emergencial a um de seus membros, na perspectiva do cuidado centrado na família, e intervir diante do sofrimento familiar identificado, tem se tornado uma exigência 
crescente na área da saúde e, especificamente, da enfermagem, tanto no âmbito da prática e do ensino, como da pesquisa ${ }^{(10)}$.

Dessa forma, acredita-se que os achados desta investigação podem cooperar para o entendimento mais profícuo das vivências e necessidades particulares das famílias que experienciam o atendimento em unidades emergenciais. Isso, por sua vez, tem potencial para promover maior sensibilização nos profissionais de saúde para o adequado acolhimento das demandas assistenciais mais elementares das famílias e qualificar a atenção, o que, por conseguinte, acarreta maior satisfação nos familiares com o serviço de saúde.

Destarte, mediante a seguinte pergunta de investigação "Como os familiares dos pacientes perceberam a vivência do atendimento de emergência?", este estudo teve como objetivo compreender como a família percebe a vivência do atendimento emergencial a um de seus membros.

\section{Método}

Estudo descritivo, de natureza qualitativa, realizado em três municípios de pequeno porte, do norte do estado do Paraná e suas respectivas unidades de pronto atendimento públicas. Os entrevistados foram identificados em maio de 2015, com base em um registro feito pelos enfermeiros dos diferentes plantões. Todos os enfermeiros foram orientados pelos pesquisadores a abordar os familiares de pacientes graves (classificados como vermelho no protocolo de acolhimento com classificação de risco), após o atendimento inicial e a estabilização do quadro clínico do paciente. Nessa abordagem, eles deveriam explicar suscintamente os objetivos da pesquisa para os familiares e reforçar que não se tratava de uma atividade da instituição de saúde, e que a participação era voluntária. Caso os familiares permitissem, os enfermeiros registravam os dados de identificação (nome completo, endereço e telefone) para posterior contato.

Todas as semanas, os pesquisadores iam até as unidades investigadas e acessavam as informações que haviam sido registradas pelos enfermeiros, e, com base nesses dados, ocorreu a seleção dos participantes. O contato com as famílias para o agendamento das entrevistas ocorreu aproximadamente 30 dias após o atendimento na unidade de emergência, de modo a permitir um tempo mínimo para que o participante pudesse refletir acerca da experiência frente ao cuidado prestado a seu familiar e significar sua percepção. Assim, a coleta de dados foi realizada em junho de 2015.

Inicialmente os investigadores contatavam, por telefone, os potenciais participantes do estudo e verificavam se estas pessoas atendiam aos critérios de inclusão selecionados: possuir 18 anos ou mais e ter acompanhado o familiar classificado como vermelho no protocolo de acolhimento utilizado nas unidades emergenciais. Em seguida, considerando dia e horário mais oportunos aos familiares, era agendado uma visita domiciliar. Para fins deste estudo, considerou-se como familiar a pessoa que, ao acompanhar o paciente na unidade de emergência, se identificava para o enfermeiro como seu familiar, independente do grau de parentesco existente.

Participaram da pesquisa 16 familiares, sendo 5 oriundos da Unidade A, 5 da Unidade B e 6 da Unidade C. Ressalta-se que participou das entrevistas domiciliares apenas o familiar que acompanhou o paciente no serviço emergencial, não havendo a interação de outros membros da família.

As entrevistas, que duraram em média 45 minutos, foram guiadas pela seguinte questão norteadora: "Conte-me suas percepções sobre como foi vivenciar o atendimento ao seu familiar naquele dia em que buscaram o pronto atendimento municipal." O total de participantes no estudo foi determinado ao se considerar o critério da saturação dos dados. Desse modo, a busca por novos informantes findou quando os discursos começaram a se tornar repetitivos ${ }^{(11)} \mathrm{e}$ o objetivo da pesquisa respondido.

As falas foram gravadas, transcritas na íntegra e submetidas à Análise de Conteúdo, modalidade temática ${ }^{(12)}$. Seguiram-se as seguintes etapas: pré-análise, exploração do material e tratamento dos dados. Na fase de pré-análise 
ocorreu a transcrição das falas, com posterior organização e separação do material empírico. Após, procedeu-se a leitura flutuante dos dados, com identificação dos aspectos emergentes e relevantes para o atendimento do objetivo proposto para a presente pesquisa. Durante a exploração do material foi realizada a classificação e agregação dos incidentes, desenvolvida após um processo minucioso e exaustivo de leitura, seguida de identificação e recorte dos aspectos que eram comuns e específicos, o que originou as categorias preliminares. E, ao final, na fase de tratamento dos dados, as categorias foram aprofundadas, mediante a articulação dos dados iniciais com a literatura acerca do tema.

A pesquisa foi desenvolvida em conformidade com as diretrizes disciplinadas pela Resolução n. 466/12, do Conselho Nacional da Saúde, e seu projeto aprovado pelo Comitê Permanente de Ética em Pesquisa com Seres Humanos da Instituição signatária (Parecer n. 1.166.681; CAAE: 43765315.7.0000.0104). Todos os entrevistados assinaram o Termo de Consentimento Livre e Esclarecido (TCLE) em duas vias. A fim de manter o anonimato, os participantes foram identificados por meio de codinomes, compostos pelo parentesco do entrevistado com o paciente e o diagnóstico de seu familiar.

\section{Resultados}

Participaram 16 familiares de pacientes atendidos nas unidades emergenciais, com idades entre 23 e 80 anos, dos quais 13 eram do sexo feminino, 12 da raça/cor branca, 5 cônjuges, 4 mães, 4 filhos(as), 2 pais e 1 nora. Com relação à escolaridade, 9 tinham ensino fundamental completo, 4 ensino médio completo, 2 ensino superior completo e 1 era analfabeto funcional.

No concernente aos diagnósticos clínicos dos pacientes que impulsionaram a busca pelo serviço de saúde, verificou-se que: seis ocorreram por problemas cerebrovasculares, três por causas externas, dois por complicações agudas de doença oncológica, um por processo alérgico, um por intoxicação exógena, um por crise convulsiva, um por desidratação severa, e um por agravamento de doença pulmonar obstrutiva crônica. Destaca-se que seis pacientes evoluíram para óbito, cinco foram transferidos para outras unidades de saúde com maior aporte tecnológico, e cinco receberam alta da unidade emergencial, das quais somente duas ocorreram no mesmo dia.

As categorias que emergiram neste estudo revelam como os participantes perceberam o atendimento prestado aos familiares e a si próprio na unidade emergencial. De modo geral, as famílias perceberam a vivência da situação com intenso sofrimento, caracterizado pelos entrevistados como experienciar um "turbilhão de sentimentos" [código in vivo] que envolvia tristeza, angústia, desespero, medo do desconhecido e da perda. Foram destacados que fatores como rapidez e resolutividade no atendimento inicial, presença de comunicação efetiva, com oferta de informação e atenção e possibilidade de acompanhar o cuidado dentro da sala de emergência, constituíam, quando presentes, qualificadores do atendimento. Isso desencadeou uma percepção positiva nos familiares e facilitou a vivência da situação crítica.

Por outro lado, quando esses mesmos fatores supracitados não estavam presentes, as famílias percebiam o atendimento de forma negativa. Nos depoimentos, pode-se verificar também que tais fatores interferentes na percepção familiar do atendimento não estavam isolados ou eram estanques. Em realidade, inter-relacionavam-se mutuamente, pois as vivências e necessidades das famílias no serviço emergencial eram complexas, e a satisfação com a assistência dependia do atendimento integral de tais necessidades (Figura 1). 
FIGURA 1- Percepção e necessidades da família durante o atendimento emergencial

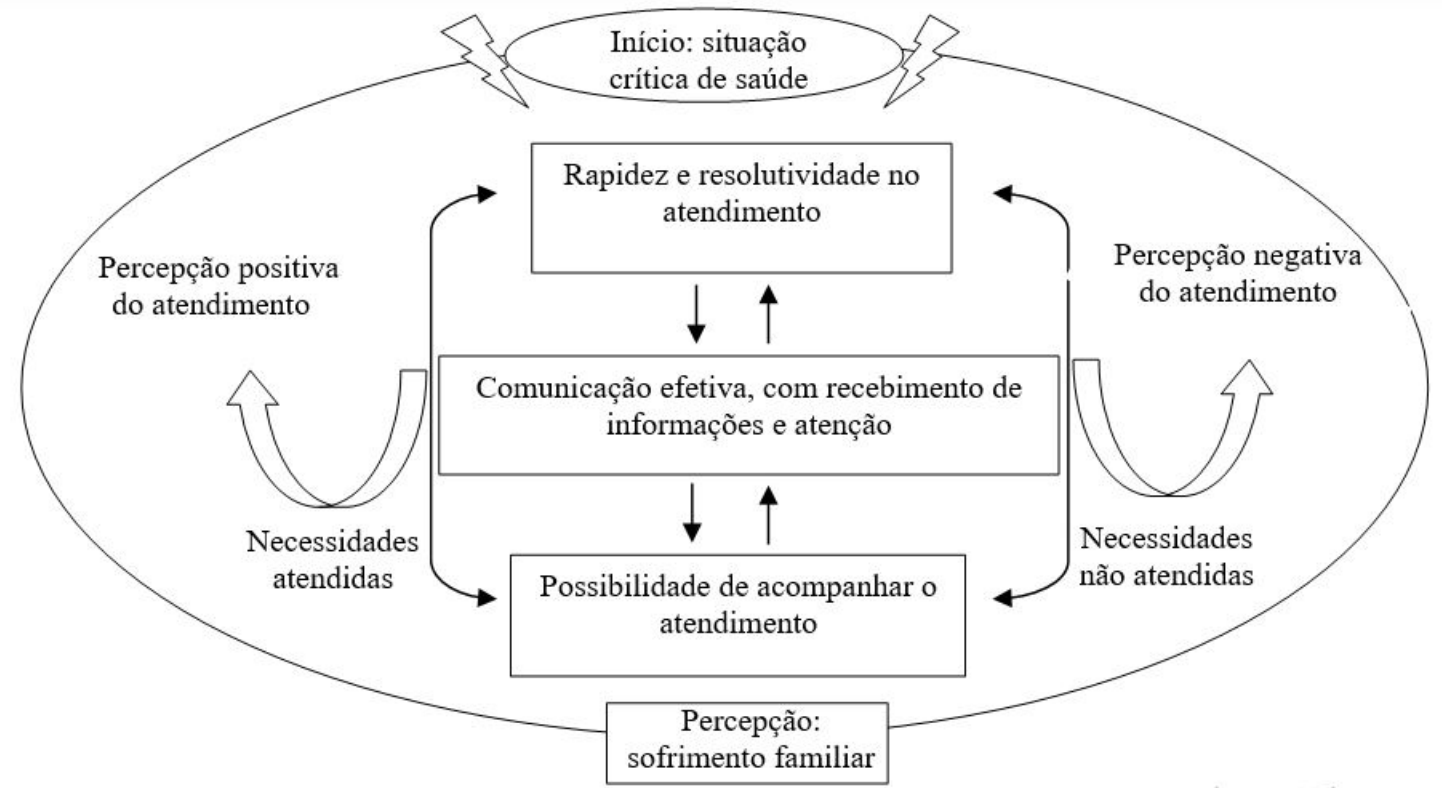

Fonte: Elaboração própria.

Todo o processo analítico dos dados levou à identificação de duas categorias temáticas, a saber: "Percepção positiva do atendimento: reconhecendo as peculiaridades de um cuidado adequado" e "Percepção negativa do atendimento: as barreiras enfrentadas pelos familiares", que serão descritas a seguir.

\section{Percepção positiva do atendimento: reconhecendo as peculiaridades de um cuidado adequado}

Ainda que o sofrimento tenha sido descrito como intenso, o atendimento ao paciente e à família foi percebido de maneira positiva pela maior parte dos entrevistados (11 casos). O contentamento foi expresso com a rapidez na prestação da assistência e com a resolutividade do problema que motivou a procura do serviço de saúde, principalmente por meio do encaminhamento do paciente a outras unidades hospitalares de maior complexidade e aporte tecnológico que permitissem a continuidade do tratamento:

Naquele dia foi tudo muito tumultuado, todo mundo sofreu com a preocupação. Mas mesmo assim eu consigo ver que o atendimento foi de qualidade [...] foi tudo muito rápido aqui no pronto socorro, atenderam ele muito rápido e já mandou para a UTI. Eles disseram que lá iria tratar melhor do problema dele. (Nora 01, familiar com Doença Pulmonar Obstrutiva Crônica).
Não foi fácil passar por aquilo tudo antes dele falecer toda aquela angústia do atendimento, pedindo a Deus pela vida dele. Mas, temos que crer que Deus foi misericordioso, porque Ele colocou profissionais bons em nosso caminho que atenderam com muita agilidade e preocupação, isso foi bom. (Esposa 02, familiar com Acidente Vascular Encefálico Hemorrágico).

$\mathrm{Na}$ percepção do familiar, a agilidade com que o atendimento foi prestado, a demonstração de preocupação com o paciente e a resolutividade inicial, mediante o encaminhamento para outros serviços de saúde, constituíram indicadores de boa qualidade do atendimento. Notou-se, também, que a transferência do familiar para um serviço de referência, com suporte tecnológico mais avançado, tranquilizava os familiares, pois percebiam uma continuidade no atendimento prestado.

Outro aspecto relevante apontado pelos familiares foi a oferta de informações sobre o quadro clínico do ente querido e as palavras de conforto e confiança proferidas pelos profissionais:

No meio daquele turbilhão de sentimentos e de coisas que estavam acontecendo, a enfermeira parou e falou comigo, disse que ele estava vivo, o médico veio depois e me explicou que ele teve um infarto, que era para eu ter calma e fé, que tudo iria dar certo, eu gostei dessa atenção que recebi. (Esposa 01, familar com Infarto Agudo do Miocárdio).

O médico conversou bastante comigo, jogou limpo, falou para eu ter calma, mas que o caso era bem grave. Disse também que eu tinha que ficar firme e forte, porque ele precisava de nós e nós dele. A enfermeira também 
conversou comigo, falou que ele estava bem, tentou me animar, falou que iria dar tudo certo, isso me acalmou naquela hora. (Filha 03, familiar com Crise Convulsiva).

Pode-se verificar que a aproximação do profissional de saúde junto aos familiares obteve repercussões positivas. Segundo os relatos, receber informações sobre o estado de saúde do familiar ou mesmo atenção, por meio de palavras de conforto, representava um aspecto que facilitava a vivência da situação, ao promover o sentimento de calma entre os familiares.

Os participantes, ao acompanharem o atendimento na sala de emergência, também perceberam a situação com intenso sofrimento. Porém, de certa forma, sentiam-se mais confortados por poderem estar próximos, e com isso, as percepções com relação à equipe e a assistência recebida eram mais positivas: Nossa! Aquele dia foi difícil, mas com relação a mim, não
tenho do que reclamar, pois me deram atenção, me dei-
xaram entrar na sala de emergência para estar com ele,
me explicaram tudo certinho, e logo já fomos encami-
nhados para o Hospital Universitário. (Mãe 02, familiar
com Intoxicação Exógena).

O atendimento foi melhor do que eu esperava, pois eles me deixaram participar de tudo, fiquei o tempo todo na sala de emergência com minha mãe, isso me confortou muito. (Filha 04, familiar com Insuficiência Cardíaca Congestiva).

Dessa forma, apreendeu-se que os familiares sentiram-se mais seguros e confortados quando autorizada sua permanência na sala de emergência para o acompanhamento integral dos cuidados prestados. Como os familiares sabem que permanecer com o paciente na sala de emergência é algo pouco usual na realidade cotidiana, eles se surpreenderam positivamente com a assistência ao vivenciar tal situação.

\section{Percepção negativa do atendimento: as barreiras enfrentadas pelos familiares}

Ao se depararem com entraves durante o atendimento de emergência, alguns familiares (cinco casos) demonstraram, por meio de suas falas, que a falta de comunicação por parte dos profissionais de saúde, a demora para o atendimento e a pouca resolutividade da assistência repercutiram de forma negativa na satisfação com o serviço, despertando, por vezes, ou mesmo intensificando, o sofrimento familiar:
Fiquei triste por ele não ter sido o primeiro a ser atendido, pois estava mal [...] Poderia ter sido melhor o atendimento, deveriam ter vindo conversar comigo, tentado me acalmar, fiquei sozinha, em pé, no corredor. Depois eu questionei sobre o quadro dele, ai que me pediram para sentar numa salinha e esperar. (Esposa 03, familiar com Infarto Agudo do Miocárdio).

Não fizeram quase nada pelo meu filbo, nem me deram informação nenhuma, nem se ele estava vivo ou morto [...] o atendimento foi péssimo, ninguém poderia fazer isso com um pai, é muito duro. (Pai 01, familiar Vítima de Acidente de Trânsito).

Além disso, evidenciou-se que os familiares almejavam estar próximos, receber informações e serem percebidos como parte integrante de suas vidas, por meio do recebimento de atenção dos profissionais de saúde.

\footnotetext{
Naquele momento de sofrimento e desespero, sem saber de nada, ainda você é mal atendido? O médico nem olhou na minha cara. Isso que mais angustia a gente, poderia ter sido melhor. (Esposa 04, familar com Infarto Agudo do Miocárdio).

A enfermeira me maltratou, também me pediu para sair da sala de emergência. Eu não queria ficar lá fora, meu filho estava com medo e chorando, eu apenas precisava cuidar dele. (Pai 02, familiar com Choque Anafilático por Intoxicação Exógena).
}

Já ouvi dizer que eles têm que atender o familiar também, mas acho que em nosso município as enfermeiras não têm esse treinamento. Os profissionais nem me olharam ou falaram direito comigo, só me mandaram ficar no canto quieta. Nem imaginam o que eu e minha mãe passamos naquele dia. (Filha 02, familiar com Parada Cardiorrespiratória após queda).

Foi perceptível a insatisfação de alguns entrevistados ao se sentirem mal acolhidos e pouco informados nos serviços de emergência. Salienta-se, em particular, a exígua atenção do profissional, ao mesmo tempo em que se relaciona esse tipo de conduta com o desconhecimento e a desqualificação profissional. Isso intensificava a vivência de sentimentos negativos acerca do serviço, como angústia, por parte dos familiares.

\section{Discussão}

Os achados deste estudo permitiram identificar que os entrevistados vivenciaram o atendimento emergencial de seu familiar com intenso sofrimento. Tal momento foi permeado por medos e angústias, porém isso não impediu que a maioria percebesse e qualificasse a assistência como positiva. Dessa maneira, relataram estar satisfeitos ao observarem a dedicação e a 
Mayckel da Silva Barreto, Sonia Silva Marcon, Cristina Garcia-Vivar,

preocupação dos profissionais, o que refletia, nos participantes, sentimentos de calma e satisfação com o serviço de saúde. Entretanto, alguns entrevistados perceberam que o sofrimento foi intensificado pela falta de comunicação, atenção e resolutividade e pela impossibilidade de estar com o familiar durante a assistência, o que culminou com a percepção de pior atendimento.

Os profissionais de saúde necessitam compreender o atendimento de emergência com base na ótica do cuidado integral. Isso porque, a vivência de uma situação crítica envolve um contexto amplo, no qual a unidade familiar está inserida e, por isso, também necessita ser cuidada. Mesmo nos casos de sobrecarga do cuidado crônico, rotineiramente, as famílias desejam estar com o paciente ${ }^{(13)}$. Logo, ao vivenciar uma situação de doença/agravo inesperado ou agudização de condição crônica em um de seus membros, a família requer atenção, pois, na maior parte dos casos, sente-se desamparada, frágil e impotente ${ }^{(9)}$. Nesse sentido, os achados deste estudo permitiram identificar demandas assistenciais que as famílias de pacientes gravemente enfermos apresentam durante a prestação da assistência, as quais, por vezes, não são consideradas pelos profissionais de saúde dos serviços emergenciais.

É necessário destacar que a maior parte das demandas apresentadas pelas famílias estava relacionada à conduta profissional, e não à estrutura física inadequada ou a falta de recursos humanos, argumentos que os profissionais comumente utilizam para justificar o não acolhimento das famílias nos serviços de emergência ${ }^{(14)}$. Assim, acredita-se que a maneira como o profissional recebe e acolhe o paciente e sua família na unidade emergencial influencia diretamente na percepção que ela possui do atendimento, além de ser capaz de ocasionar estresse e intenso sofrimento em todo o contexto familiar.

Corroborando tal achado, pesquisa realizada com oito familiares e quatro pacientes atendidos na emergência de um hospital público brasileiro identificou que os membros da família que se sentiam melhor atendidos, e assim manejavam e vivenciavam melhor a situação, foram justamente aqueles que apontaram receber informações de maneira antecipada, ainda durante a realização da assistência $^{(8)}$.

Nessa perspectiva, entende-se que a família necessita de cuidados distintos, na mesma medida que os pacientes, pois ao enfrentar a internação de um familiar em setores críticos, a família apresenta sentimentos de fragilidade e desamparo ${ }^{(1)}$. Dessa forma, ao assistir a família em suas diversas necessidades e estabelecer junto a ela um processo comunicacional eficaz, claro e objetivo, os profissionais da saúde podem proporcionar a cada membro familiar o reconhecimento dos pontos fortes, e assim, contribuir de modo que todos os integrantes vivenciam os momentos críticos.

Quando o profissional, principalmente o enfermeiro, reconhece que tanto o paciente como a família necessitam de cuidados, ele é capaz de realizar atitudes simples, como demonstrar desvelo às demandas e aos sentimentos, e com isso, promover a motivação do restante da equipe, o que culmina em uma assistência integral, humana e holística. Para além, estudo realizado com familiares de pacientes gravemente enfermos identificou que deve ocorrer a busca pela integralidade da assistência por parte da equipe de saúde, sobretudo da enfermagem, visto que as necessidades apresentadas pelos familiares demonstravam a premência de incorporar a família como parte do cuidado, formando um binômio indissociável: paciente/família ${ }^{(15)}$.

Todavia, concernente a este acolhimento à família, são notáveis o despreparo e a exígua sensibilização dos profissionais. Estudos realizados no Brasil ${ }^{(16)}$, Estados Unidos ${ }^{(17)}$, Austrália ${ }^{(18)}$ e na Finlândia ${ }^{(19)}$ constataram que os profissionais de saúde consideram a participação do familiar no atendimento de emergência um empecilho, em função dos questionamentos e da atenção que a família requer. Tal postura acarreta condutas que não atendem de maneira qualificada as demandas familiares e resultam no sofrimento e na insatisfação das famílias diante do atendimento que é prestado no serviço de emergência.

Nesse sentido, evidências científicas ${ }^{(7,16)}$ apontam que a participação familiar no cuidado crítico e agudo é crucial, para que ela observe os esforços de salvamento da vida de seu parente, 
assim como receba informações de maneira antecipada. Destarte, há maior tendência de se melhorar o atendimento ao desencadear maior segurança e apoio emocional ao paciente durante toda a assistência ${ }^{(7)}$. O presente estudo contribuiu ao identificar que a entrada do familiar na sala de emergência acarretou maior segurança emocional para o familiar.

Mesmo que a inserção dos familiares na sala de emergência seja uma realidade distante na maioria das unidades de pronto atendimento brasileiras, especialmente pela precariedade de infraestrutura física para receber esta família, pelo déficit de pessoal da equipe de enfermagem ou pelo próprio despreparo e inexperiência dos profissionais de saúde em compreender as atribuições da família no espaço de cuidado emergencial $^{(20)}$, é urgente que os profissionais atuantes nesses setores, tão logo seja possível e de maneira paulatina, acolham as famílias, prestando-lhes informações, já que, na presente investigação, pode-se constatar que o sofrimento dos familiares foi potencialmente agravado quando a comunicação não era eficaz.

Ainda nesse contexto, a falha de comunicação consiste importante barreira nos serviços de emergência, pois sua manutenção compromete a integralidade do cuidado prestado, com prejuízo emocional para o núcleo familiar ${ }^{(8)}$. Assim, essas famílias precisam de explicações cuidadosas, tempo para processar a informação recebida e o apoio profissional consistente para capacitá-las à tomada de decisão e facilitar o enfrentamento dos desafios ${ }^{(7)}$.

Corrobora ainda tais informações, estudo realizado no Chile, com 30 familiares de pacientes atendidos em uma unidade de emergência ${ }^{(6)}$. Inferiu-se que, segundo o familiar, a relação com a equipe era tênue, a comunicação praticamente inexistia e muitos buscavam interpretar os gestos e as atitudes dos profissionais para compreender o que ocorria. Desse modo, reitera-se que a comunicação configura-se como elemento-chave para a oferta de orientações e para o estabelecimento de confiança entre a tríade profissional-família-paciente. Uma comunicação efetiva ameniza as angústias durante esse momento estressor e potencializa a sensação de segurança tanto para o paciente como para a família, além de colaborar com a recuperação do doente ${ }^{(16)}$.

Nota-se ainda, que a equipe de saúde necessita de capacitação sobre essa temática, uma vez que a deficiência de conhecimento foi percebida pelo familiar e caracterizada como qualificação precária. Estudo realizado junto a 160 enfermeiros atuantes em 2 serviços de emergência da Irlanda do Norte apontou que a maioria reconhecia o cuidado holístico centrado na família durante e após o atendimento de emergência como um dever profissional, contudo, isso não ocorria, dentre outros fatores, pela inadequada formação. À luz dessa constatação, os autores sugeriram que os enfermeiros deveriam participar de sessões de educação continuada e programas de acompanhamento, para melhor preparar as equipes profissionais no que tange ao acolhimento das famílias nos serviços de emergência ${ }^{(14)}$.

Outro estudo realizado junto a enfermeiros de uma unidade de cuidados críticos australiana evidenciou que a formação acadêmica era tida como inadequada, no tocante a preparação para o atendimento às necessidades de cuidados complexos das famílias nos momentos que antecedem e seguem a morte de pacientes ${ }^{(21)}$. Nesse sentido, as evidências mais atuais demonstraram que há um impacto positivo do preparo profissional nas atitudes dos provedores em relação à presença da família no cuidado crítico ${ }^{(22)}$. Assim, o preparo profissional pode melhorar a atuação dos profissionais de saúde na emergência, favorecer o vínculo e a confiança entre pacientes, familiares e profissionais, principalmente na oferta de orientações, e promover acolhimento multidisciplinar. Além disso, quando o profissional se aproxima da família ele tem uma chance única de se fazer presente e empático nessa relação, o que traz benefícios para todo o núcleo familiar nessa instância de cuidados. Manter comunicação assertiva com a família e acolhê-la podem ser o alicerce para o atendimento individualizado, que contempla subjetividades inerentes ao ser humano. Para tanto, é necessário profissionalismo ético e sensível ${ }^{(23)}$.

Reforça-se a imperiosa necessidade de os profissionais de saúde acolher e inserir as famílias no espaço de cuidado ao paciente gravemente 
Mayckel da Silva Barreto, Sonia Silva Marcon, Cristina Garcia-Vivar,

enfermo, não somente porque ela pode constituir fonte de informação acerca do quadro de saúde do paciente para a equipe de saúde, mas, principalmente, por constituir fonte de apoio para o enfrentamento e sofrimento vivenciado nas unidades emergenciais pelo paciente e demais membros da família.

Possíveis limitações do estudo referem-se ao fato de os enfermeiros das unidades terem sido responsáveis pela identificação e indicação dos potenciais participantes e, como estavam cientes do objetivo do estudo, poderem, em certa medida, ter modificado suas atitudes em relação aos familiares; ainda, o fato de as entrevistas terem ocorrido cerca de 30 dias após a experiência dos familiares na emergência, o que pode acarretar o viés de esquecimento.

\section{Conclusão}

A percepção da vivência familiar durante o atendimento emergencial é caracterizada por intenso sofrimento, diretamente influenciado pelo modo como os profissionais recebem e acolhem o paciente e sua família. Segundo os familiares, o atendimento prestado foi, em sua maioria, percebido como satisfatório, sendo considerado nessa percepção fatores como: comunicação assertiva, oferta de atenção, resolutividade inicial do problema de saúde por meio da agilidade na transferência para um serviço de saúde com maior aporte tecnológico, e a possibilidade de estar com o familiar na sala de emergência durante o atendimento. Por outro lado, na percepção dos familiares, a ausência desses fatores caracterizou mau atendimento, o que incrementava o sofrimento familiar, dificultando ainda mais a vivência da situação.

Os achados deste estudo avançaram no conhecimento por apontarem a urgente necessidade de se discutir e preparar melhor os profissionais de saúde para uma atuação mais qualificada junto às famílias nos setores emergenciais.

\section{Colaborações}

1 - concepção, projeto, análise e interpretação dos dados: Mayckel da Silva Barreto, Sonia Silva Marcon e Cristina Garcia-Vivar;
2 - redação do artigo e revisão crítica relevante do conteúdo intelectual: Mayckel da Silva Barreto, Sonia Silva Marcon, Cristina Garcia-Vivar, Eleandro do Prado, Josane Rosenilda da Costa, Patrícia Chatalov Ferreira e Ricardo de Souza Campos Seguraço;

3 - aprovação final da versão a ser publicada: Mayckel da Silva Barreto, Sonia Silva Marcon, Cristina Garcia-Vivar, Eleandro do Prado, Josane Rosenilda da Costa, Patrícia Chatalov Ferreira e Ricardo de Souza Campos Seguraço.

\section{Referências}

1. Flannery L, Ramjan LM, Peters K. End-of-life decisions in the Intensive Care Unit (ICU) Exploring the experiences of ICU nurses and doctors - A critical literature review. Aust Crit Care. 2015;28(4):1-8. DOI: https://doi.org/10.1016/j. aucc. 2015.07.004

2. Acosta AM, Marques GQ, Levandovski PF, Peralta JP, Lima MADS. Satisfação dos usuários com cuidados de enfermagem em serviço de emergência: uma revisão integrativa. Rev min enferm. 2016;20:e938. DOI: http://www.dx.doi. org/10.5935/1415-2762.20160008

3. Antunes BCS, Crozeta K, Assis F, Paganini MC. Rede de atenção às urgências e emergências: perfil, demanda e itinerário de atendimento de idosos. Cogitare Enferm. 2018;23(2):e53766. DOI: http://dx.doi.org/10.5380/ce.v23i2.53766

4. Roncalli AA, Oliveira DN, Silva ICM, Brito RF, Viegas SMF. Protocolo de Manchester e população usuária na classificação de risco: visão do enfermeiro. Rev baiana enferm. 2017;31(2):e16949. DOI: 10.18471/rbe.v31i2.16949

5. Gomes ATL, Ferreira-Júnior MA, Salvador PTCO, Bezerril MS, Chiavone FBT, Santos VEP. Safety of the patient in an emergency situation: perceptions of the nursing team. Rev Bras Enferm. 2019 Jun;72(3):753-9. DOI: https://doi. org/10.1590/0034-7167-2018-0544

6. Dall'Orso MS, Concha PJ. Presencia familiar durante la reanimación cardiopulmonar: la mirada de enfermeros y familiares. Cienc enferm. 2012;18(3):83-99. DOI: http://dx.doi.org/ 10.4067/S0717-95532012000300009

7. Mekitarin FFP, Angelo M. Family's presence in the pediatric emergency room: opinion of health professionals. Rev Paul Pediatr. 2015;33(4):460-6. DOI: 10.1016/j.rpped.2015.03.010 
8. Barreto MS, Garcia-Vivar C, Matsuda LM, Angelo M, Oliveira MLF, Marcon SS. Presença da família durante $\mathrm{O}$ atendimento emergencial: vivência de pacientes e familiares. Texto Contexto Enferm. 2019;28:e20180150. DOI: http://dx.doi. org/10.1590/1980-265X-TCE-2018-0150

9. Soares JR, Martin AR, Lopes APAT, Marcon SS, Barreto MS. Possibility of accompanying emergency care from a family perspective: a descriptive study. Online braz j nurs. 2017;16(1):188-98. DOI: https:// dx.doi.org/10.17665/1676-4285.20175585

10. Barreto MS, Arruda GO, Garcia-Vivar C, Marcon SS. Cuidado centrado na família em unidades emergenciais: percepção de enfermeiros e médicos brasileiros. Esc Anna Nery. 2017;21(2):e20170042. DOI: https://doi.org/ 10.5935/1414-8145.20170042

11. Minayo MCS. Amostragem e saturação em pesquisa qualitativa: consensos e controvérsias. Rev Pesq Qualitativa[Internet]. 2017 [cited2020Jan5];5(7):1-12. Available from: https://editora.sepq.org.br/index. $\mathrm{php} / \mathrm{rpq} / \mathrm{article} / \mathrm{view} / 82 / 59$

12. Bardin L. Análise de Conteúdo. 7a ed. São Paulo: Edições 70; 2016.

13. Arruda GO, Leal LB, Peruzzo HE, Nass EMA, Reis P, Marcon SS. Percepções da família acerca do cuidado ao homem com alguma condição crônica. Ciênc Cuid Saúde. 2018;17(1):268-74. DOI: 10.4025cienccuidsaude.v17i1.43845

14. McLaughlin K. Family-centred care during resuscitation events. Emerg Nurse. 2013;21(3):28-34. DOI: $10.7748 / \mathrm{en} 2013.06 .21 .3 .28 . e 1152$

15. Vasconcelos EV, Freitas KO, Silva SÉD, Baia RSM, Tavares RS, Araújo JS. O cotidiano de familiares de pacientes internados na UTI: um estudo com as representações sociais. J res: fundam care online. 2016;8(2):4313-27. DOI: 10.9789/2175-5361.2016. v8i2.4313-4327

16. Barreto MS, Peruzzo HE, Garcia-Vivar C, Marcon SS. Family presence during cardiopulmonary resuscitation and invasive procedures: a metasynthesis. Rev esc enferm USP. 2019;53:e03435. DOI: https://doi.org/10.1590/s1980-220x2018001303435
17. Twibell R, Siela D, Riwitis C, Neal A, Waters N. A qualitative study of factors in nurses' and physicians' decision-making related to family presence during resuscitation. J Clin Nurs. 2018;27(1-2):e320-34.DOI:https://doi.org/10.1111/ jocn. 13948

18. Giles T, Lacey S, Muir-Cochrane E. Factors influencing decision-making around family presence during resuscitation: a grounded theory study. J Adv Nurs. 2016;72(11):2706-17. DOI: https://doi.org/10.1111/jan.13046.

19. Sak-Dankosky N, Andruszkiewicz P, Sherwood PR, Kvist T. Health care professionals' concerns regarding in-hospital family-witnessed cardiopulmonary resuscitation implementation into clinical practice. Nurs Crit Care. 2018;23(3):134-40. DOI: https://doi.org/10.1111/nicc.12294

20. Barreto MS, Marcon SS, Garcia-Vivar C. Patterns of behaviour in families of critically ill patients in the emergency room: a focused ethnography. J Adv Nurs. 2017;73(3):633-42. DOI: https://doi. org/10.1111/jan.13156

21. Bloomer MJ, Morphet J, O'Connor M, Lee S, Griffiths D. Nursing care of the family before and after a death in the ICU - An exploratory pilot study. Aust Crit Care. 2013;26(1):23-8. DOI: https:// doi.org/10.1016/j.aucc.2012.01.001

22. Powers K. Educational interventions to improve support for family presence during resuscitation: A systematic review of the literature. Dimens Crit Care Nurs. 2017;36(2):125-38. DOI: 10.1097/ DCC.0000000000000228

23. Luiz FF, Caregnato RCA, Costa MR. Humanização na Terapia Intensiva: percepção do familiar e do profissional de saúde. Rev Bras Enferm. 2017;70(5):1095-103.DOI:http://dx.doi.org/10.1590/ 0034-7167-2016-0281

Recebido: 8 de janeiro de 2020

Aprovado: 11 de março de 2020

Publicado: 13 de abril de 2020

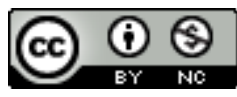

A Revista Baiana de Enfermagem utiliza a Licença Creative Commons - Atribuição-NãoComercial 4.0 Internacional. https://creativecommons.org/licenses/by-nc/4.0/

Este artigo é de acesso aberto distribuído sob os termos da Licença Creative Commons (CC BY-NC).

Esta licença permite que outros remixem, adaptem e criem a partir do seu trabalho para fins não comerciais. Embora os novos trabalhos tenham de lhe atribuir o devido crédito e não possam ser usados para fins comerciais, os usuários não têm de licenciar esses trabalhos derivados sob os mesmos termos. 